\title{
Media Transportation and Advertising
}

\author{
JING WANG \\ BOBBY J. CALDER*
}

\begin{abstract}
Advertising is commonly presented in the context of media articles or programs that are intended to engage the consumer. An important aspect of this engagement is media transportation, where a person not only attends to information but also is absorbed into the narrative flow of a story in a pleasurable and active way. This research examines the effects of the transportation experience produced by the media context on the impact of ads that appear in that context. Three studies show that transportation can have both positive and negative effects on advertising. Intrusion of the ad into the transportation process is shown to mediate the negative effects, which occurs independently of involvement.
\end{abstract}

$\mathrm{T}$ here are many theoretical reasons to expect that consumer reactions to advertising are affected by their response to the program or print material in which the advertising is inserted. Indeed many studies have looked at the impact of media context on the effectiveness of advertising. At present, however, two major issues arise with this literature. One concerns the need for more specific theories about how media context can affect advertising. The other relates to when context affects advertising positively and when it affects it negatively.

\section{THE TRANSPORTATION EXPERIENCE}

This research focuses on a specific theory of one way that context can affect advertising - the transportation experience. Perhaps an example from a qualitative interview will help to make immediately clear the nature of the transportation experience. A female consumer is describing the experience of reading a particular magazine:

I do a lot of reading while I am sitting down eating . . . if I am eating alone. . . . I pull the magazine over and start flipping through it. And sometimes I sit there at the table for an hour or so and continue reading articles that appeal to me. . . . I get caught up in the articles.

\footnotetext{
*Jing Wang is assistant professor of marketing at Henry B. Tippie College of Business, University of Iowa, Iowa City, Iowa 52242 (jing-wang@uiowa .edu). Bobby J. Calder is the Charles H. Kellstadt Distinguished Professor of Marketing and Psychology and professor of journalism in the Marketing Department, Kellogg School of Management, Northwestern University, Evanston, IL 60208 (calder@kellogg.northwestern.edu). The authors thank Gregory S. Carpenter, Kent Grayson, Dawn Iacobucci, Angela Y. Lee, Edward C. Malthouse, and Brian Sternthal for their helpful comments.
}

Dawn Iacobucci served as editor and Mary Frances Luce served as associate editor for this article.

Electronically Published July 31, 2006
Now certainly not all consumers experience transportation all the time or to the same degree. But most of us experience transportation to some extent with some kinds of media (e.g., magazines, television, movies, and theater).

Green and Brock $(2000,701)$ recently have sought to define the concept of transportation theoretically as "a convergent process, where all mental systems and capacities become focused on events occurring in the narrative." Transportation is the extent of absorption into the narrative flow of the story as it unfolds. They show that high transportation leads to more change in story-related beliefs and evaluations than does low transportation.

Transportation has also been implicated in three other lines of theory. Most generally, Csikszentmihalyi (1990, 1997, 2000) discusses experiences that are ends in themselves and are not tied to external considerations. The individual is caught up in the "flow" of the experience of an activity and absorbed into it. This work highlights the notion that flow is a pleasurable experience, and we build on this notion below in relating the level of transportation produced by the media context to advertising. A second line of theorizing (Roche and McConkey 1990; Tellegen and Atkinson 1974) examines the tendency of individuals to be absorbed as a chronic dispositional trait rather than, as the case here, as an acute response to the particular content of a story. Finally, the work of Gerrig (1993; Polichak and Gerrig 2002) emphasizes that transportation is characterized by "participatory responses," which are thoughts actively generated in response to the narrative. While such cognitive responses do not define transportation, they do indicate that transportation can be an active process.

There has also been relevant research in the consumer behavior literature. Deighton, Romer, and McQueen (1989), following Wells (1988), contend that more dramatic television commercials are processed differently from more argumentoriented ones. More recently, Escalas (2004b) finds that narrative ad processing is positively correlated with brand atti- 
tudes and behavioral intentions. According to Escalas (2004a), a narratively structured ad persuades people by connecting the ad to the self via narrative transportation. In our view, transportation is at least as much of an issue with media context as with ads per se since transportation is very often a goal of media.

\section{Media Transportation and Advertising Effectiveness}

The present research program focuses on how differences in transportation affect an ad that is presented in the context of the story (i.e., where the story is the media context for the ad). Previous work has not addressed this issue; it is first necessary to extend transportation theory to encompass such effects. We propose that these effects depend not only on the extent to which the audience is transported by the context but also on the relationship between the ad exposure and the transportation experience. Specifically, high transportation should enhance advertising effectiveness if the ad exposure does not interrupt the transportation experience.

With high transportation, people are absorbed in the media context and experience it as a pleasurable activity. If an ad does not interfere with this process, say by occurring after the story is completed, the positive experience of transportation will be associated with the ad. This should lead to greater advertising effectiveness. However, if the ad interrupts the transportation experience, this in itself creates a negative experience that is associated with the ad. This should lead to lower advertising effectiveness.

\section{Transportation versus Involvement}

Another goal of this research is to relate transportation both theoretically and empirically to the construct of involvement. Involvement is, of course, one of the most widely used constructs in behavioral research. It has been applied directly to the problem at hand. Unfortunately, these studies have yielded inconsistent results. In some studies, context involvement enhances ad effectiveness, while in others context involvement decreases it (Anand and Sternthal 1992; Feltham and Arnold 1994; Furnham, Gunter, and Walsh 1998; Lord and Burnkrant 1993; Norris and Colman 1992; Soldow and Principe 1981). In our view, transportation offers a more specific approach to context that may lead to more consistent results.

In this connection, it is of interest to ask how transportation and involvement may be differentiated. Johnson and Eagly (1989) perhaps provide the most extensive analysis of the involvement construct. They conclude that involvement is a motivational state in which a person's self-concept is activated in terms of her or his ability to obtain desired outcomes (see also Petty and Cacioppo 1979; Sherif and Cantril 1947; Zaichkowsky 1985). In contrast, transportation is a state or experience "where all mental systems and capacities become focused on events occurring in the narrative" (Green and Brock 2000, 701). It necessarily makes use of cognitive processes like attention, comprehension, and imagery, but these are not the defining characteristics. Transportation is different from involvement in that the person feels caught up in the story itself and not in any consequences extrinsic to the narrative. This parallels the distinction between intrinsic and extrinsic motivation that is widely accepted in the task performance literature (Calder and Staw 1975; Deci and Ryan 1985; Lepper and Greene 1978). We return to the issue of transportation versus involvement in our last study by examining the joint effects of the two variables.

\section{STUDY 1}

In our opening discussion, we advanced the theory that the effect of transportation on attitudes toward an advertised product is moderated by whether the ad intrudes on the transportation experience. Transportation should lead to a less favorable product attitude when the ad is intrusive, but transportation should lead to a more favorable product attitude when the ad is not intrusive. In this study, we test this theory by varying the position of the ad such that the ad interrupts the transportation experience in one position (in the middle of the story) but not in the other (at the end of the story). Thus, the study design was a 2 (transportation: high vs. low) $\times 2$ (ad position: middle vs. end) between-subjects design, where transportation was a measured variable. Participants' attitudes toward the product, the ad, and the story, as well as the extent to which they were transported, were collected as dependent variables.

We also included dependent variables to assess perceptions of ad intrusiveness and alternative negative reactions to the ad. Our theory predicts effects for the former variable but not the latter. This nonequivalent control dependent variable approach provides an even stronger test of construct validity-allowing us to distinguish between intrusiveness and other negative reactions to the ad (for which effects are not predicted).

\section{Method}

Stimuli. The story (titled "Coffee Shop Kindness," taken from Chicken Soup for the College Soul) is about a college student and a depressed customer who help cheer each other up by being considerate and caring. The story was four pages long. A full-page ad for Wendy's (created for this research, see fig. 1) was inserted either after the second or the last page.

Procedure. Fifty-six undergraduate students (28 males; average age $=20.25$ ), who participated for extra class credits, were randomly assigned to one of the two ad position conditions. Participants were told that the purpose of the study was to evaluate prototype material for a new magazine concept. They were told that they were reading a sample story and that a sample ad would appear in the prototype. They were further told that they would complete a questionnaire about the magazine after reading the prototype. After reading the story, they expressed their attitudes toward Wendy's on a four-item seven-point scale $(1=$ dislike very much/very 


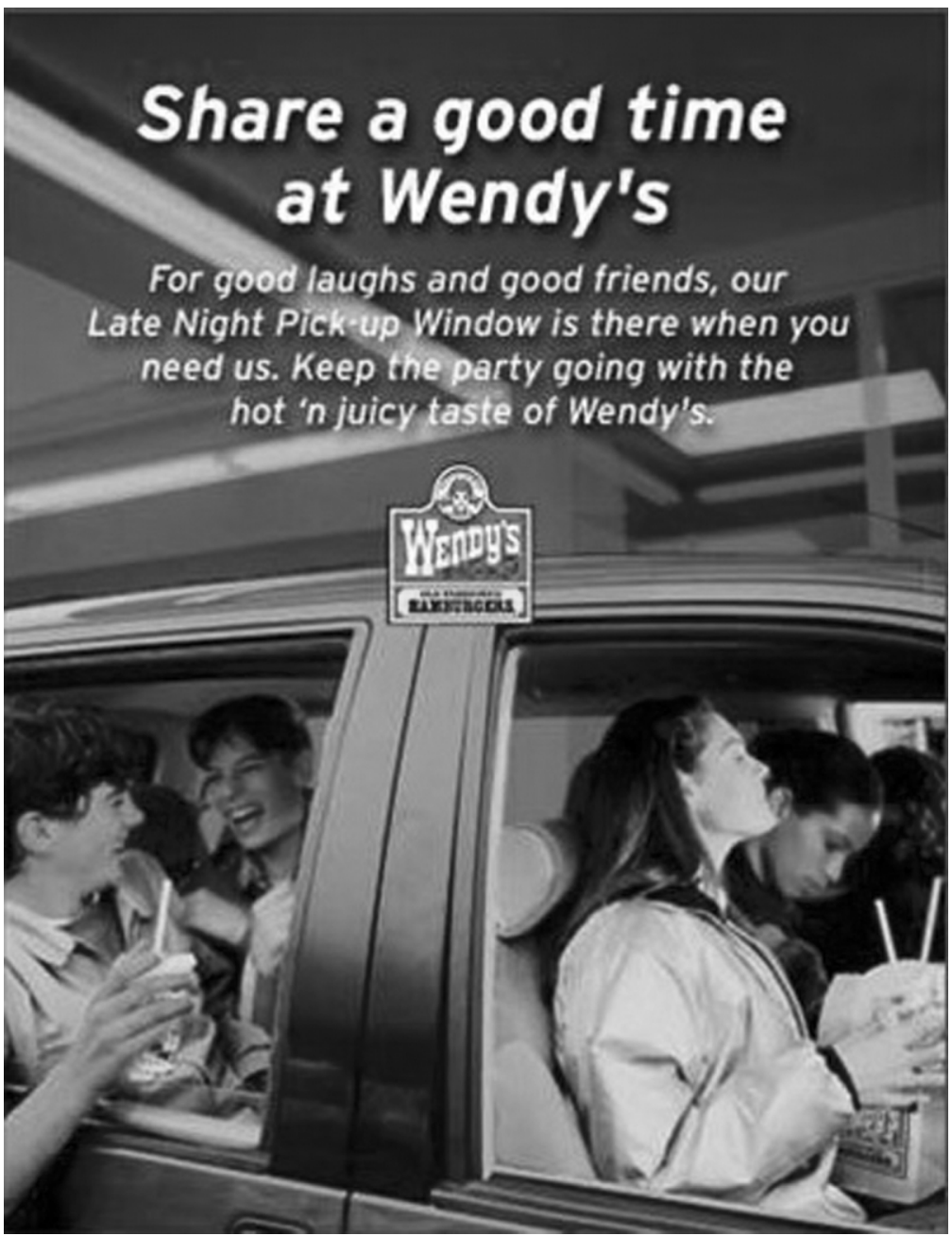

NotE.-A color version of this ad is available as an online enhancement.

unfavorable/not at all attractive/very bad; 7 = like very much/ very favorable/very attractive/very good).

Then perceived ad intrusiveness was measured with a seven-point scale $(1=$ not at all; $7=$ very much $)$ on seven items (distracting, disturbing, forced, interfering, intrusive, invasive, and obtrusive). To distinguish the proposed theoretical mechanism of intrusion from other, more general negative reactions to the ad, we employed a nonequivalent control variable strategy (see Cook and Campbell 1979). A sevenpoint scale of five items was used (irritating, phony, ridiculous, stupid, and terrible); none of the items related to intrusion, but they did relate to other possible alternative negative reactions to an ad. If predicted effects are obtained for the perceived ad intrusion dependent variable but not for the ad negativity control variable, these effects provide additional evidence that it is indeed the intrusion mechanism operating and not some other process of negative affect. (These two scales were taken from Edwards, Li, and Lee [2002], who distinguish intrusion from overall irritation with an ad.) Finally, participants evaluated the story on a five-item sevenpoint scale ( $1=$ awful/dislike very much/not at all interesting/ not very well written/not at all involving; $7=$ excellent/like very much/very interesting/very well written/very involving) and completed a transportation measure adapted from Green and Brock (2000), indicating how much they agreed with each of 15 statements $(1=$ very slightly or not at all; $5=$ extremely).

\section{Results}

Participants' ratings on the transportation scale were summed to form transportation scores $(\alpha=.72)$. Then par- 
ticipants were categorized into high versus low transportation groups with a median split on the transportation scores, thus forming a measured treatment variable.

Product Attitude. We predicted that, when the ad is inserted in the middle of the story and interrupts the transportation experience, highly transported participants should develop less favorable attitudes toward the advertised product than less transported participants. However, when the $\mathrm{ad}$ is at the end of the story and does not interrupt the transportation experience, a higher level of transportation should lead to more favorable product attitudes. Participants' ratings on the four items were combined to form a product attitude index $(\alpha=.97)$. A 2 (transportation) $\times 2$ (ad position) ANOVA on the index showed a main effect of ad position. Participants had more favorable product attitudes when the ad was inserted at the end of the story than when it was inserted in the middle of the story $(M=4.70 \mathrm{vs}$. $M=3.77 ; F(1,52)=4.33, p<.05)$. More importantly, the main effect of ad position was qualified by an interaction of transportation and ad position $(F(1,52)=10.77, p<$ $.01)$. Subsequent planned contrast showed that, when the ad was at the end of the story, participants had more favorable product attitudes when they were more transported than when they were not $(M=5.36$ vs. $M=4.04 ; t(52)=$ $2.09, p<.05)$. However, when the ad was inserted in the middle of the story, participants had less favorable product attitudes when they were more transported than when they were $\operatorname{not}(M=2.96$ vs. $M=4.57 ; t(52)=2.55, p=$ .01 ; see fig. 2).

Story Evaluation. To ensure that the product attitude results cannot be accounted for by participants' attitude toward the story, we asked them to evaluate the story. We predicted that participants who were more transported by the story would evaluate the story more favorably than those less transported, independent of the position of the ad. Their ratings on the five story evaluation items were combined into a story evaluation index $(\alpha=.91)$. As predicted, results of a 2 (transportation) $\times 2$ (ad position) ANOVA on the story evaluation index showed only a significant main effect of transportation $(M=4.61$ vs. $M=3.11 ; F(1,52)=$ $25.01, p<.001)$. Neither the main effect of ad position $(F<1)$ nor the interaction $(F(1,52)=1.42, p>.2)$ was significant. The fact that the results for story evaluation did not parallel those for product attitude supports our hypothesis that story evaluation does not account for the transportation effect on product attitude. This hypothesis was further supported by adding story evaluation as a covariate in product attitude analyses. The critical interaction between transportation and ad position remained significant even after controlling for story evaluation $(F(1,51)=10.58, p<$ $.01)$. In a final analysis of product attitude, transportation was replaced with story evaluation (also with a median split). The story attitude $\times$ ad position interaction was not significant $(F<1)$. (Parallel analyses on story evaluations were also conducted for the next two studies. Across the studies, the results consistently showed that the effects of
FIGURE 2

\section{STUDY 1: PRODUCT ATTITUDE AS A FUNCTION OF TRANSPORTATION AND AD POSITION}

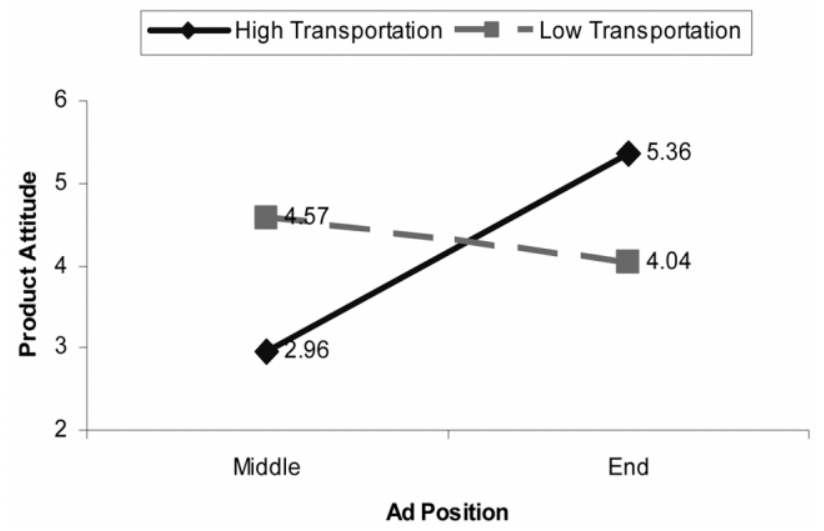

transportation on product attitude could not be accounted for by participants' story evaluations.)

Perceived Ad Intrusiveness. We predicted that the ad should be more intrusive to the transportation experience when it is in the middle of the story than when it is at the end. Furthermore, we predicted that the ad in the middle of the story is more intrusive to highly transported participants than to those less transported. Participants' ratings on the seven items measuring intrusiveness were averaged to form an index of perceived ad intrusiveness $(\alpha=.88)$. A 2 (transportation $) \times 2$ (ad position) ANOVA on the index showed a main effect of ad position and a marginal main effect of transportation. As predicted, participants perceived the ad to be more intrusive when it was in the middle of the story than when it was at the end $(M=4.29$ vs. $M=$ $3.19 ; F(1,52)=8.55, p<.01)$. Highly transported participants perceived the ad to be marginally more intrusive than less transported participants $(M=4.07$ vs. $M=$ $3.40 ; F(1,52)=3.18, p=.08)$. More importantly, the main effects were qualified by a significant interaction of transportation and ad position $(F(1,52)=10.39, p<.01)$. Consistent with our hypotheses, planned contrasts revealed that, when the ad was at the end of the story, highly transported participants perceived the ad to be equal in intrusion to less transported participants $(M=2.92$ vs. $M=3.46$; $t(52)=1.02, p>.3)$. However, when the ad was in the middle of the story, highly transported participants perceived the ad to be more intrusive than their less transported counterparts $(M=5.22$ vs. $M=3.35 ; t(52)=3.54, p=$ .001 ; see fig. 3$)$.

Ad Negativity Control Variable. We predicted that the reduced ad effectiveness comes from perceived ad intrusiveness and not from some other general negative reactions to the ad. Therefore, we did not expect any effect on this control variable as a function of the two factors. Participants' ratings on the five items making up this variable were av- 
FIGURE 3

STUDY 1: PERCEIVED AD INSTRUSIVENESS AS A FUNCTION OF TRANSPORTATION AND AD POSITION
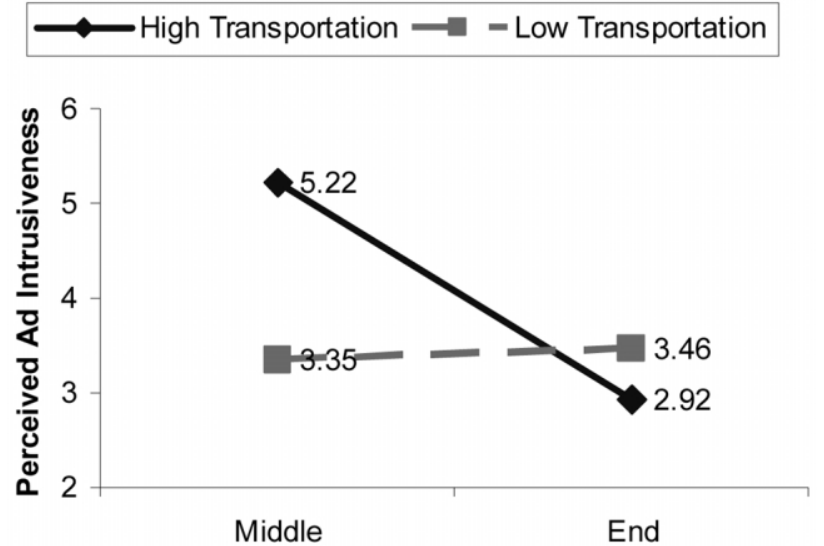

Ad Position

eraged to form an index $(\alpha=.76)$. As predicted, a 2 (transportation $) \times 2$ (ad position) ANOVA on the index showed that neither the main effects $\left(F_{\mathrm{S}}<1\right)$ nor the interaction $(F(1,52)=1.19, p>.2)$ was significant.

Mediation Analyses. We not only hypothesized that the relationship between ad exposure and context transportation moderates the effect of transportation on product attitude but also predicted that, when the ad does intrude on the transportation experience, perceived ad intrusiveness mediates the effect of transportation on product attitude. To investigate this moderated mediation, we conducted mediation analyses separately for the two ad position conditions. When the ad appeared in the middle of the story, the effect of felt transportation on product attitude $(b=-.13$; $t(26)=-2.80, p<.01)$ and on perceived ad intrusiveness $(b=.12 ; t(26)=2.78, p=.01)$ were both significant. However, when transportation and perceived ad intrusiveness were both included in the model, the effect of transportation on product attitude became nonsignificant $(b=$ $-.06 ; t(25)=-1.39, p>.10)$, whereas the effect of perceived ad intrusiveness on product attitude was significant $(b=-.54 ; t(25)=-2.98, p<.01)$. The result of the Sobel test (Baron and Kenny 1986) showed that the mediating effect of perceived ad intrusiveness was significant $(z=$ $2.03 ; p<.05)$. These results support our hypotheses that the effect of transportation on product attitude is mediated by perceived ad intrusiveness when the ad intrudes on the transportation experience. A parallel analysis using the ad negativity control variable showed that it does not mediate the effect of transportation on product attitude; the effect of transportation on the ad negativity control variable failed to reach significance $(b=.02 ; t(26)<1, p>.50)$.

When the ad appeared at the end of the story, the effect of transportation on product attitude was significant $(b=$ $.09 ; t(26)=2.07, p<.05)$. However, the effect of trans- portation on perceived ad intrusiveness was not significant $(b=-.04 ; t(26)=-1.02, p>.30)$. Therefore, perceived ad intrusiveness could not mediate the effect of transportation on product attitude. This is consistent with our hypothesis that the product benefits from the positive association with the transportation experience when the ad is not intrusive.

\section{Discussion}

Results of this study not only showed that an ad inserted in the middle of a transporting story leads to a less favorable attitude toward the advertised product; they also shed light on the mechanism underlying such effects. Specifically, when the ad was inserted in the middle of the story, highly transported participants perceived the ad to be more intrusive than those who were less transported. Consequently, the former developed less favorable product attitudes than the latter. Results of the mediation analyses showed that perceived ad intrusiveness indeed mediated the effect of transportation on product attitude.

Also, as predicted, the pattern was reversed when the ad did not interrupt the transportation experience. When the ad was inserted at the end of the story, that is, when the transportation experience was not interrupted, the ad benefited from the pleasurable experience of transportation, such that those who were more transported had more favorable attitudes toward the advertised product than those who were less transported. Also consistent with our hypotheses, participants perceived the ad to be equally nonintrusive when the ad did not interrupt the transportation experience. This served as a boundary condition for demonstrating the negative transportation effect on product attitude. However, future research is also warranted to examine possible mechanisms underlying the positive transportation effect on product attitude.

In sum, these findings show that transportation in the medium surrounding an ad can have both positive and negative effects on reactions to the ad, depending on the position of the ad. Moreover, the position manipulation supports the theory that it is the intrusion of the ad into the transportation process that produces the negative effect. When the ad is in the middle of the story, it clearly is more disruptive to transportation than at the end. The process measure of intrusiveness in this study confirms this. The result is strengthened by the fact that the nonequivalent dependent variable measure of ad negativity does not show any effect.

In study 2 we try to pin down further that transportation is a type of information processing and that what is crucial is whether an ad intrudes on this processing. We seek to show that having an ad in the middle of a story does not always lead to a negative effect. Whether it does or not depends on the effect of the ad on the transportation process. On a more methodological note, the manipulation of intrusion in this first study, that is, placing the ad in the middle or at the end of the story, might lead to the speculation that the results could come from the position rather than the intrusion (among other things, the time between ad exposure 
and evaluation is different across the conditions). This methodological issue is addressed in the next study by having the ad always appearing in the middle of the story.

\section{STUDY 2}

In this study we directly tie the extent to which an ad requires information processing resources to the extent to which it will intrude on the transportation process. An ad that makes heavy processing demands will take away more from the transportation process than one that makes lighter processing demands. Thus, in this study, we operationalize intrusion in terms of the extent to which the ad requires processing resources that might otherwise be used in the transportation process.

The intrusiveness of the ad in this study was manipulated by varying the relevance of the product to participants' salient goals. When the ad is of greater personal relevance, participants are more likely to pay attention to it and to process it deeply. As a result, the ad will be more intrusive to the transportation experience (it takes more resources away from it) and highly transported participants should have a less favorable attitude toward the advertised product because of the interrupted transportation experience. On the other hand, the same ad that is irrelevant to a salient goal should be less likely to interrupt the context transportation experience. Consequently, the product attitude should be less influenced by how transporting the context is. In short, we hypothesized that personal goal relevance of the ad could exacerbate the negative effects of interrupted transportation on advertising effectiveness, whereas the goal irrelevance of the ad should alleviate such effects and leave the product attitude less affected.

This study thus investigates whether transportation and personal goal relevance of the ad act together to affect advertising effectiveness. A 2 (transportation: high vs. low) $\times 2$ (ad-goal relevance: relevant vs. irrelevant) between-subjects design was employed. Participants read a story with an ad always inserted in the middle of the story. Transportation was a measured variable, and personal goal relevance of the ad was manipulated by priming participants with relevant versus irrelevant goals. We predict that an ad relevant to the salient goal is more intrusive to participants' transportation experience and should be evaluated less favorably.

\section{Method}

Stimuli. To add to the robustness of our findings, we changed the story to a classic short story by O'Henry ("After Twenty Years"). Two childhood friends meet again after 20 yr. and turn out to be a policeman and a criminal. The policeman has to arrest his friend, but, in a surprise ending, manages to escape doing this himself. An ad for a fictitious product that could be used by all participants, Pure bottled water, was created for the research. The story was three pages long and the full-page ad for Pure bottled water was inserted between the second and the third pages for all participants (see fig. 4 for the ad).
Procedure. A two-study, unrelated tasks procedure was used. Fifty undergraduate students ( 25 males; average age $=$ 20.58), who participated for extra class credit, were told that they would participate in two unrelated studies. One study was about shopping for a very important social event. In the goal-relevant condition, participants were told that they would be responsible for getting beverages, such as soda or bottled water, for the social event; in the goal-irrelevant condition, they were told that they would be responsible for getting snacks.

In the second study, participants were told that they would help evaluate a new magazine concept by reading a sample story from the first issue. Participants read the O'Henry story with the bottled water ad in the middle. After that, they indicated how much attention they had paid to the ad, evaluated the product and the story, and responded to the transportation scale.

\section{Results}

Participants' ratings on the transportation measure were combined to form transportation scores $(\alpha=.75)$. Then participants were categorized into two (high vs. low) transportation groups with a median split on the transportation scores.

Manipulation Check. Participants were asked to indicate how much attention they had paid to the inserted ad. We predicted that participants who had the goal of getting beverages should pay more attention to the ad for bottled water than those who had the goal of getting snacks. A 2 (transportation) $\times 2$ (ad-goal relevance) ANOVA supported our hypotheses by identifying only a main effect of ad-goal relevance. Participants with the goal of getting beverages reported paying more attention to the bottled water ad than those with the goal of getting snacks $(M=5.74$ vs. $M=$ $2.70 ; F(1,46)=54.81, p<.001)$, indicating that our manipulation successfully directed participants' attention to a goal relevant ad, thereby requiring more resources.

Product Attitude. We hypothesized that an ad relevant to a salient personal goal should require more resources, and therefore be more intrusive to transportation, and should be evaluated less favorably when participants are highly transported than when they are not. However, an ad irrelevant to the salient personal goal is less likely to be intrusive and, as a result, the transporting nature of the story should have less influence on product attitude. Participants' ratings on the four items were averaged to form a product attitude index $(\alpha=$ .92). Consistent with our hypotheses, a 2 (transportation) $\times$ 2 (ad-goal relevance) ANOVA on the product attitude index revealed a marginal main effect of ad-goal relevance and a main effect of transportation. Specifically, participants with the goal of getting beverages evaluated the bottled water marginally less favorably than those with the goal of getting snacks $(M=3.65$ vs. $M=4.33 ; F(1,46)=3.41, p=$ $.07)$, suggesting the negative influence of a relevant goal on advertising effectiveness. In addition, participants eval- 
FIGURE 4

AD FOR PURE BOTTLED WATER

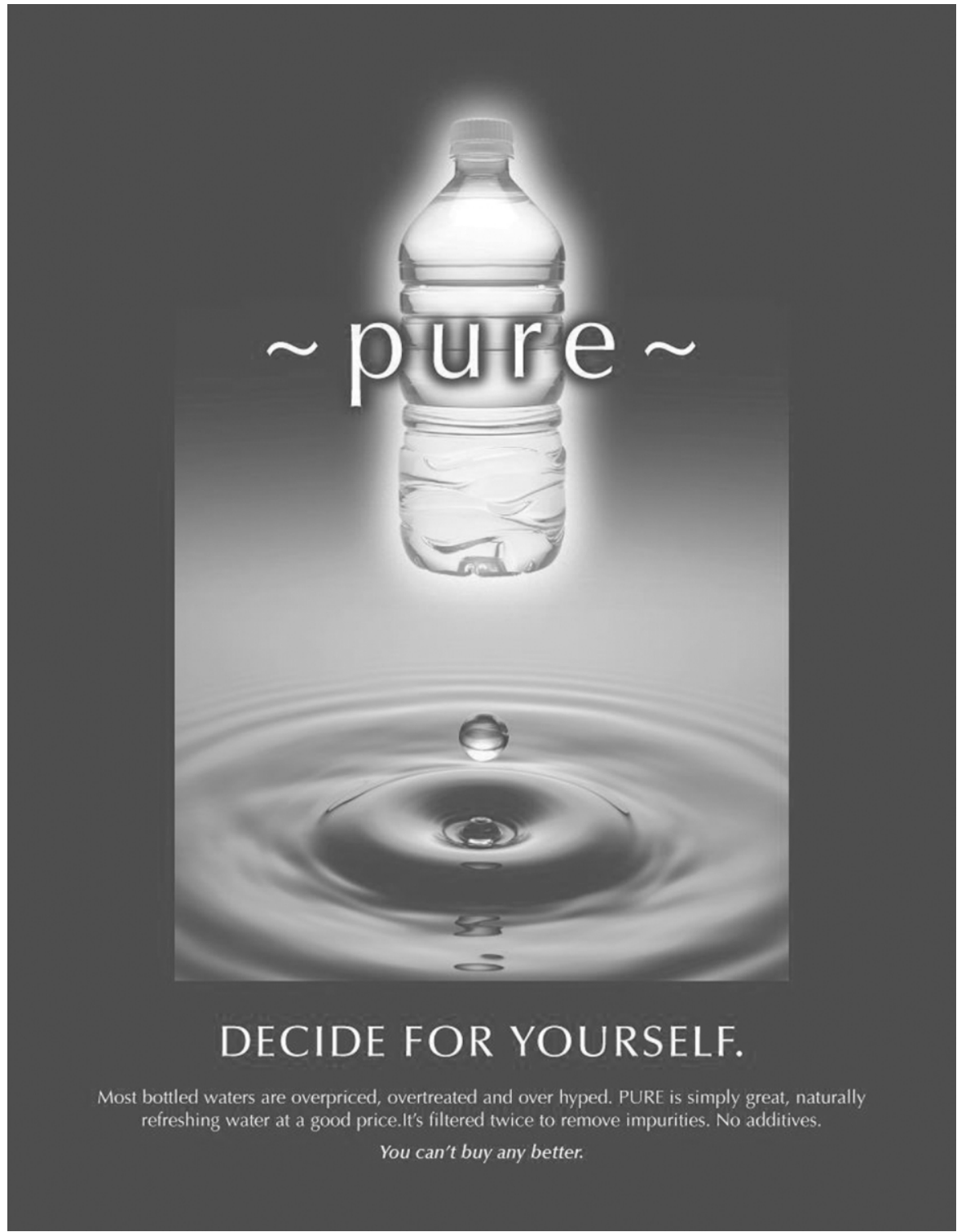

NOTE.-A color version of this ad is available as an online enhancement.

uated the product less favorably when they were highly transported than when they were not $(M=3.57$ vs. $M=$ $4.46 ; F(1,46)=9.59, p<.01)$, indicating the negative influence of context transportation on advertising effectiveness. More importantly, the interaction of transportation and ad-goal relevance was also significant $(F(1,46)=19.18$, $p<.001)$. Subsequent planned contrasts showed that, when the ad was irrelevant to their goal, participants developed equally favorable product attitudes regardless of whether they were highly transported $(M=4.49)$ or not $(M=$ $4.18 ; t(46)<1, p>.4)$. However, when the ad was relevant to their goal, highly transported participants evaluated the product less favorably than their less transported counterparts $(M=2.97$ vs. $M=4.80 ; t(46)=5.84, p<.001$; see fig. 5).

\section{Discussion}

In this study, we examined how transportation interacts with the processing demands of an ad in affecting attitudes toward the advertised product. Our results showed that highly transported participants evaluated the advertised 
FIGURE 5

STUDY 2: PRODUCT ATTITUDE AS A FUNCTION OF TRANSPORTATION AND AD-GOAL RELEVANCE

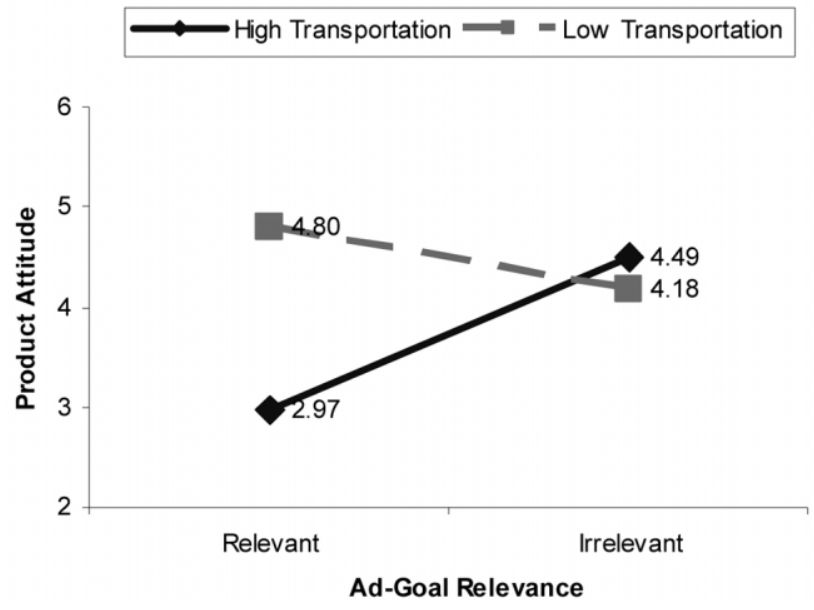

product less favorably than the less transported participants when the ad was relevant to their goals. The two groups evaluated the product equally favorably when the ad was irrelevant to their goals. The results thus support our theorizing that an ad requiring more processing (due to the goal relevance primed by the prior unrelated task) interrupts the transportation experience more, resulting in the less favorable product attitude.

Taken together these two studies offer convergent evidence for our analysis of the role of transportation in context effects on advertising. We now turn to the issue of whether the effects of transportation can be distinguished from those of involvement.

\section{STUDY 3}

Can the effects of transportation be distinguished from those of involvement? Addressing this question entails both theoretical and empirical considerations. Transportation should be distinguished theoretically from involvement in that involvement is about engagement in the instrumental outcomes of, in the present case, media usage. In contrast, transportation is about being absorbed into the media content itself. This theoretical distinction is consistent with major treatments of the involvement construct in the literature.

Additionally, a study seeking to differentiate the effects of transportation and involvement in the media context on advertising should ideally meet several empirical criteria. One criterion is having a manipulation of transportation that results in differences in the level of transportation. A second criterion is that the transportation manipulation does not affect involvement. A third criterion is having an involvement manipulation that demonstrates that involvement differences are possible in the situation. If all three of these criteria are met and the effect of transportation on an ad is observed, then the effect of transportation apart from involvement is demonstrated.

Using this approach, we manipulate both transportation and involvement in this study. A 2 (transportation: high vs. low) $\times 2$ (involvement: high vs. low) between-subjects design was used along with three key dependent variables, measured transportation, measured involvement, and reactions to an advertised product. The media context story was the same as that used in study 1 , and the Pure ad was inserted in the middle of the story for all participants. Involvement was manipulated, consistent with the theoretical distinction above, by varying the personal consequence of the story. Similar manipulations of involvement have been used by Burnkrant and Howard (1984), Leippe and Elkin (1987), Petty and Cacioppo (1979, 1981, 1984), Petty, Cacioppo, and Goldman (1981), and Petty, Cacioppo, and Heesacker (1981). While the focus of this study is not on involvement per se, but rather on distinguishing transportation from involvement, the effect of involvement on product attitude is of interest in its own right given the previous findings of both negative and positive effects.

This study extends the first two studies by treating transportation as a manipulated variable rather than a measured one. We varied transportation by altering the chronological flow of the story. Specifically, in the high transportation condition, the story had a smooth, linear chronological flow, whereas in the low transportation condition, this flow was reordered to be less smooth. (The content of the story remained the same in both conditions.) This method has been used by Voss, Wiley, and Sandak (1999), among others. While manipulated variables, just as measured ones, are not uniquely associated with underlying theoretical constructs, we feel that using both types of treatments adds to the robustness of our research program.

\section{Method}

Procedure. Forty-eight undergraduate students (21 males; average age $=22.51$ ), who participated for extra class credits, were randomly assigned to one of the four conditions. The general cover story was the same as those used in the previous studies. In the high-involvement condition, participants were told that they were to evaluate the concept for a new campus magazine for the coming academic year. This magazine would have articles on various issues related to college students, and the authors would be students in the same university, so the implications would apply directly to them. Participants were further told that they were among a selected sample of students for whom the issues in the magazine would be directly relevant.

On the other hand, participants in the low-involvement condition were told that they were to evaluate the concept for a new magazine that might be circulated in some cities in a few years. This magazine would have articles on various issues, and the authors would be ordinary people, not students like them. Participants were further told that they were among a large sample of different kinds of people randomly 
selected from the general population, and they were told to read the story as they would any general interest magazine article.

Participants evaluated the product, the ad, and the story with the same scales used in previous studies and completed the transportation scale. To check the involvement manipulation, a four-item seven-point scale was added. Participants indicated how they felt when they were reading the story $(1=$ not at all involved/not at all interested/skimmed it quickly/paid little attention; $7=$ very involved/very interested/read it carefully/paid a lot of attention).

\section{Results}

Manipulation Checks. To distinguish the effects of transportation from those of involvement, we need to show that our transportation manipulation affects felt transportation but not felt involvement and that our involvement manipulation affects felt involvement. Participants' ratings on the 15 items of the transportation measure were combined to form a transportation score for each participant $(\alpha=$ .85 ), and their ratings on the four items of the involvement measure were combined to form an involvement score for each participant $(\alpha=.91)$. Two 2 (transportation) $\times 2$ (involvement) ANOVAs of the transportation and involvement scores showed that the criteria were met. As predicted, participants in the high transportation condition (i.e., who read the story in the chronological order) were more transported than those in the low transportation condition (i.e., who read the story in the disrupted chronological order; $M=47.55$ vs. $M=38.85 ; F(1,44)=12.99, p=.001)$, whereas the former did not report to be more involved than the latter $(M=5.35$ vs. $M=4.99 ; F(1,44)=1.40, p>.20)$. In addition, participants in the high involvement condition reported more involvement than those in the low involvement condition $(M=5.59$ vs. $M=4.72 ; F(1,44)=6.75, p=.01)$, indicating that it was possible for involvement to vary in this situation. As discussed above, the demonstration of these three effects allows us to differentiate the effects of transportation from those of involvement, if the effect of transportation on product attitude is still observed as in previous studies.

Product Attitude. In this study, the position of the ad was constant for all participants. It appeared in the middle of the story. As in the two prior studies, we predicted that participants in the high transportation condition should evaluate the product less favorably than those in the low transportation condition, because the product is associated with the disruption of the transportation experience. We did not have a priori prediction on the effect of story involvement on product attitude. Both positive and negative effects of context involvement have been demonstrated. What we did predict is a negative effect of transportation on product attitude, independent of how involvement affects product attitude.

Participants' ratings on the four evaluative items were averaged to form a product attitude index $(\alpha=.86)$. A 2 (transportation) $\times 2$ (involvement) ANOVA on the index revealed two significant main effects. Consistent with our hypotheses and the results in previous studies, participants in the high transportation condition evaluated the product less favorably than those in the low transportation condition $(M=4.18$ vs. $M=4.71 ; F(1,44)=6.21, p<.05)$. In addition, participants in the high involvement condition also evaluated the product less favorably than those in the low involvement condition $(M=4.21$ vs. $M=4.70 ; F(1,44)=5.37, p<$ .05; see fig. 6). This is consistent with Soldow and Principe's (1981) results, which also suggest a negative effect of context involvement on product attitude. However, whereas Soldow and Principe (1981) could have manipulated both transportation and involvement simultaneously by showing two different TV programs, our results clearly demonstrated the unique contribution of transportation and involvement separately. The lack of a significant interaction between transportation and involvement $(F<1)$ suggests that the two factors influence product attitude in an additive way.

The above main effects were also examined using the felt involvement variable as a covariate. When involvement scores were included as a covariate, the significant main effect of involvement became nonsignificant $(F(1,43)=$ $3.53, p=.07)$, whereas the main effect of transportation remained significant $(F(1,43)=5.34, p<.05)$. This analysis provides further support for the hypothesis that the effect of transportation does not depend on involvement.

Perceived Ad Intrusiveness. We predicted that the ad should be more intrusive to the transportation experience when it appears in the middle of a highly transporting story (i.e., in the chronological order) rather than in a nontransporting story (i.e., when the story order was altered). Participants' ratings on the seven items measuring intrusiveness were averaged to form an index of perceived ad intrusiveness $(\alpha=.91)$. As predicted, the 2 (transportation) $\times 2$ (involvement) ANOVA on the index showed two main effects. Par-

\section{FIGURE 6}

PRODUCT ATTITUDE AS A FUNCTION OF STORY ORDER AND INVOLVEMENT

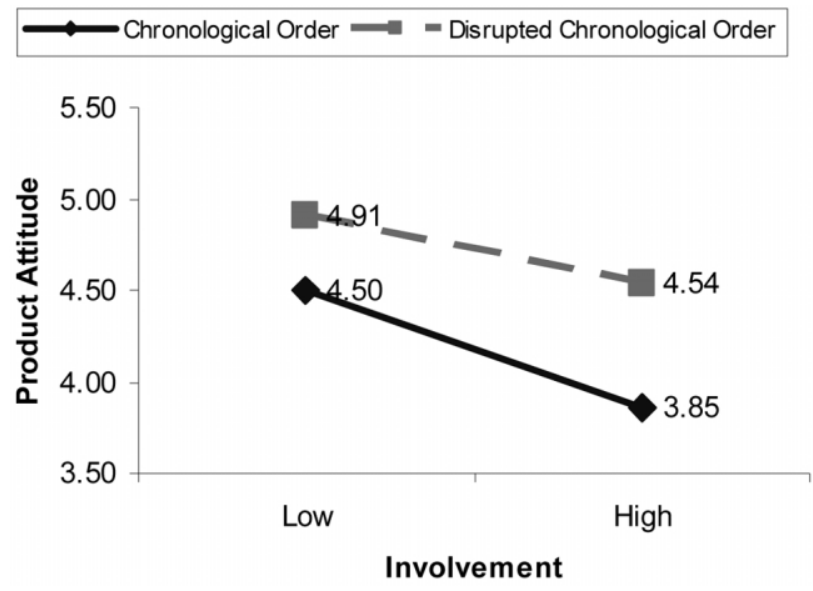


ticipants perceived the ad to be more intrusive when the story was in the chronological order than when the order was altered $(M=4.35$ vs. $M=3.51 ; F(1,44)=5.19, p<.05)$. In addition, participants perceived the ad to be more intrusive when they were highly involved than when they were not $(M=$ 4.35 vs. $M=3.47 ; F(1,44)=5.78, p<.05)$. The interaction was not significant $(F<1$; see fig. 7$)$.

Ad Negativity Control Variable. We predicted that the reduced ad effectiveness comes from perceived ad intrusiveness and not from some other general negative reactions to the ad. Therefore, we did not expect any effect on this control variable as a function of the two factors. Participants' ratings on the five items making up this variable were averaged to form an index $(\alpha=.87)$. Consistent with our predictions, a 2 (transportation) $\times 2$ (involvement) ANOVA on the index showed that neither the main effects nor the interaction $(F$ 's $<1)$ was significant.

Mediation Analyses. We hypothesized that the perceived ad intrusiveness mediates the negative effect of transportation on product attitude when the ad intrudes on the transportation experience. The mediation analyses showed that the effect of felt transportation on product attitude $(b=-.39 ; t(46)=-2.18, p<.05)$ and on perceived ad intrusiveness $(b=.73 ; t(46)=2.43, p<.05)$ were both significant. However, when transportation and perceived ad intrusiveness were both included in the model, the effect of transportation on product attitude became nonsignificant $(b=-.14 ; t(45)=-.89, p>.30)$, whereas the effect of perceived ad intrusiveness on product attitude was significant $(b=-.34 ; t(45)=-4.71, p<.001)$. The result of the Sobel test showed that the mediating effect of perceived ad intrusiveness was significant $(z=2.16 ; p<.05)$. These results support our hypotheses that the effect of transportation on product attitude is mediated by perceived ad intrusiveness when the ad intrudes on the transportation experience. A parallel analysis using the ad negativity control variable, as predicted, showed no evidence of mediation by this variable.

\section{Discussion}

High versus low transportation levels were created in this study by varying the chronological structure of the story constituting the media context for an ad. Transportation affected the product attitude resulting from the ad in the same way as in the first two studies. The effect was again shown to be mediated specifically by the perceived intrusiveness of the ad rather than any general negative reaction to the ad. Moreover, transportation was shown to operate independently of involvement. These results indicate that it is necessary to distinguish between the constructs of transportation and involvement. Could other approaches to involvement yield different results? This possibility remains open. But the present results underline the need to consider how any approach relates to transportation. It cannot be assumed that transportation necessarily equates to involvement.

\section{FIGURE 7}

STUDY 3: PERCEIVED AD INTRUSIVENESS AS A FUNCTION OF STORY ORDER AND INVOLVEMENT

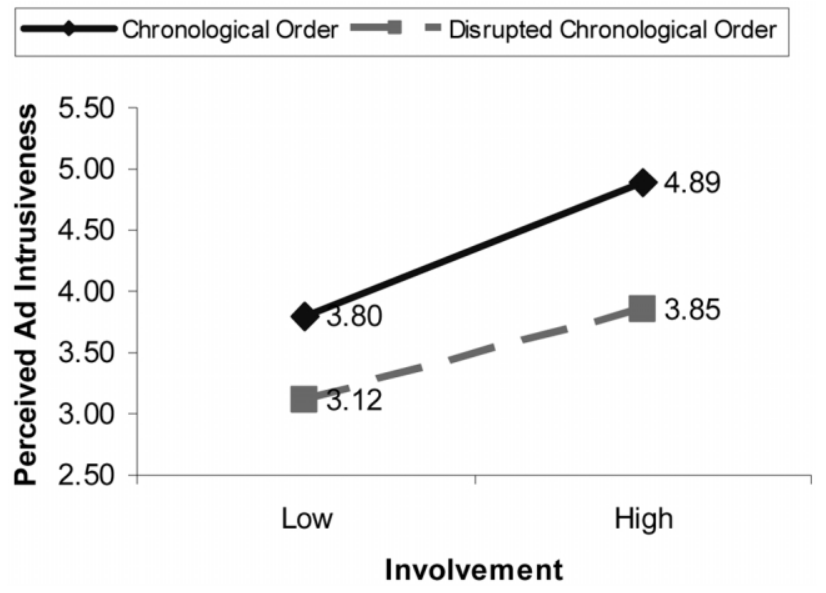

Treating transportation and involvement as separate constructs raises the issue of how the two constructs are related. One theoretical possibility is that involvement can cause transportation but that transportation does not necessarily imply involvement. In this study, the transportation manipulation did not affect felt involvement (one of our three criteria for a strong test of independence). Further, transportation still affected product attitude when involvement was used as a covariate. However, the involvement manipulation did affect felt transportation $(M=45.84$ vs. $M=$ $40.31 ; F(1,44)=5.74, p<.05)$. This is consistent with the hypothesis that involvement can lead to increases in the level of transportation. The relationship between the two variables is a promising area for future research.

\section{CONCLUSIONS}

Transportation is theoretically defined as a process of narrative information processing in which a person not only attends to information but is also absorbed into the flow of a story in a pleasurable and active way. We have proposed and shown that transportation positively affects advertising that does not intrude on the transportation process but that transportation negatively affects advertising that interrupts the transportation experience. Across three studies, we approached intrusion on the transportation process in different ways. We produced intrusion by positioning the ad in the middle of the context and intensified intrusion by creating relevance between the ad and personal goals. We reduced intrusion by positioning the ad at the end of the story and by reducing its relevance.

These findings have important implications for advertising. Media create the audience for most advertising. Consumers come to a medium for its content. Media content is experienced in many positive ways (Calder and Malthouse 2004). An important aspect of this is the transportation ex- 
perience. But the higher this media transportation is, the more likely it is to have a negative impact on advertising, if advertising intrudes on the transportation process. Advertising that is more valued by the consumer (goal relevant in this research) is even more likely to be negatively affected in this way. From both a business and a consumer point of view, there is clearly the potential here for dysfunctional consequences. Companies may actually pay more for media ad placements that lead to lower advertising effectiveness. Consumers may respond more negatively to ads that they ordinarily would be interested in. We recognize that our studies might have increased participants' attention to advertising. Note, however, that the fundamental assumption of the entire advertising industry is that consumers do pay some attention to advertising. Our results suggest that this attention to advertising could have negative effects if it interrupts consumers' contextual experiences.

Further research is needed to understand the relationship between media transportation and advertising responsiveness more fully. We have identified intrusion into the transportation process as a key factor. But what makes advertising more or less intrusive? Our results indicate that placement matters. No doubt other features of the ad matter as well. Moreover, it seems likely that the design of the medium and the way consumers use it and their expectations about it may matter. Sometimes advertising can be expected, such as during the periodic breaks in television programming. Advertising in such cases could be less intrusive because people are prepared for the ads.

In addition to the interesting issues that arise with advertising, we should return to transportation itself. Transportation is an experience that can be described qualitatively (Calder 2001). It is a common experience that almost everyone has to varying extents. A major goal of this research is to advance a more theoretical understanding of transportation, building on the work of Green and Brock (2000, 2002) and viewing transportation as narrative information processing in which a person is absorbed into the flow of a story in a pleasurable and active way. The present results support this theoretical view. Our intrusion variables can be taken as theoretical probes designed to show that transportation indeed depends on narrative information processing.

\section{REFERENCES}

Anand, Punam and Brian Sternthal (1992), "The Effects of Program Involvement and Ease of Message Counterarguing on Advertising Persuasiveness," Journal of Consumer Psychology, 1 (3), 225-38.

Baron, Reuben M. and David A. Kenny (1986), "The ModeratorMediator Variable Distinction in Social Psychological Research: Conceptual, Strategic, and Statistical Considerations," Journal of Personality and Social Psychology, 51 (6), 1173-82.

Burnkrant, Robert E. and Daniel J. Howard (1984), "Effects of the Use of Introductory Rhetorical Questions versus Statements on Information Processing," Journal of Personality and Social Psychology, 47 (6), 1218-30.
Calder, Bobby J. (2001), "Understanding Consumers," in Kellogg on Marketing, ed. Dawn Iacobucci, New York: Wiley, 151-64.

Calder, Bobby J. and Edward C. Malthouse (2004), "Qualitative Media Measures: Newspaper Experiences," International Journal of Media Management, 6 (1-2), 124-31.

Calder, Bobby J. and Barry M. Staw (1975), "Self-Perception of Intrinsic and Extrinsic Motivation," Journal of Personality and Social Psychology, 31 (4), 599-605.

Cook, Thomas D. and Donald T. Campbell (1979), Quasi-Experimentation: Design and Analysis Issues for Field Settings, Chicago: Rand McNally.

Csikszentmihalyi, Mihaly (1990), Flow: The Psychology of Optimal Experience, New York: Harper \& Row.

(1997), Finding Flow: The Psychology of Engagement with Everyday Life, New York: Basic Books.

- (2000), "The Costs and Benefits of Consuming," Journal of Consumer Research, 27 (2), 267-72.

Deci, Edward L. and Richard M. Ryan (1985), Intrinsic Motivation and Self-Determination in Human Behavior, New York: Plenum.

Deighton, John, Daniel Romer, and Josh McQueen (1989), "Using Drama to Persuade," Journal of Consumer Research, 16 (3), 335-43.

Edwards, Steven M., Hairong Li, and Joo-Hyun Lee (2002), "Forced Exposure and Psychological Reactance: Antecedents and Consequences of the Perceived Intrusiveness of Pop-Up Ads," Journal of Advertising, 31 (3), 83-95.

Escalas, Jennifer E. (2004a), "Imagine Yourself in the Product: Mental Simulation, Narrative Transportation, and Persuasion," Journal of Advertising, 33 (2), 37-48.

- (2004b), "Narrative Processing: Building Consumer Connections to Brands," Journal of Consumer Psychology, 14 (1-2), 168-80.

Feltham, Tammi S. and Stephen J. Arnold (1994), "Program Involvement and Ad/Program Consistency as Moderators of Program Context Effects," Journal of Consumer Psychology, 3 (1), 51-77.

Furnham, Adrian, Barrie Gunter, and Deidre Walsh (1998), "Effects of Program Context on Memory of Humorous Television Commercials," Applied Cognitive Psychology, 12 (6), 555-67.

Gerrig, Richard J. (1993), Experiencing Narrative Worlds: On the Psychological Activities of Reading, New Haven, CT: Yale University Press.

Green, Melanie C. and Timothy C. Brock (2000), "The Role of Transportation in the Persuasiveness of Public Narratives," Journal of Personality and Social Psychology, 79 (5), 701-21.

_ (2002), "In the Mind's Eye: Transportation-Imagery Model of Narrative Persuasion," in Narrative Impact: Social and Cognitive Foundations, ed. Melanie C. Green, Jeffrey J. Strange, Timothy C. Brock, Mahwah, NJ: Lawrence Erlbaum, 315-41.

Johnson, Blair T. and Alice H. Eagly (1989), "Effects of Involvement on Persuasion: A Meta-Analysis," Psychological Bulletin, 106 (2), 290-314.

Leippe, Michael R. and Roger A. Elkin (1987), "When Motives Clash: Issue Involvement and Response Involvement as Determinants of Persuasion," Journal of Personality and Social Psychology, 52 (2), 269-78.

Lepper, Mark R. and David Greene (1978), The Hidden Costs of Reward: New Perspectives on the Psychology of Human Motivation, Oxford: Erlbaum.

Lord, Kenneth R. and Robert E. Burnkrant (1993), “Attention versus Distraction: The Interactive Effect of Program Involve- 
ment and Attentional Devices on Commercial Processing," Journal of Advertising, 22 (1), 47-60.

Norris, Claire E. and Andrew M. Colman (1992), "Context Effects on Recall and Recognition of Magazine Advertisements," Journal of Advertising, 21 (3), 37-46.

Petty, Richard E. and John T. Cacioppo (1979), "Issue Involvement Can Increase or Decrease Persuasion by Enhancing MessageRelevant Cognitive Responses," Journal of Personality and Social Psychology, 37 (10), 1915-26.

- (1981), Attitudes and Persuasion: Classic and Contemporary Approaches, Dubuque, IA: Brown.

- (1984), "The Effects of Involvement on Responses to Argument Quantity and Quality: Central and Peripheral Routes to Persuasion," Journal of Personality and Social Psychology, 46 (1), 69-81.

Petty, Richard E., John T. Cacioppo, and Rachel Goldman (1981), "Personal Involvement as a Determinant of Argument-Based Persuasion," Journal of Personality and Social Psychology, 41 (5), 847-55.

Petty, Richard E., John T. Cacioppo, and Martin Heesacker (1981), "Effects of Rhetorical Questions on Persuasion: A Cognitive Response Analysis," Journal of Personality and Social Psychology, 40 (3), 432-40.

Polichak, James W. and Richard J. Gerrig (2002), “'Get Up and Win!': Participatory Responses to Narrative," in Narrative Impact: Social and Cognitive Foundations, ed. Melanie C. Green,
Jeffrey J. Strange, Timothy C. Brock, Mahwah, NJ: Erlbaum, 71-95.

Roche, Suzanne M. and Kevin M. McConkey (1990), “Absorption: Nature, Assessment, and Correlates," Journal of Personality and Social Psychology, 59 (1), 91-101.

Sherif, Muzafer and Hadley Cantril (1947), The Psychology of EgoInvolvements: Social Attitudes and Identifications. Oxford: Wiley.

Soldow, Gary F. and Victor Principe (1981), "Response to Commercials as a Function of Program Context," Journal of Advertising Research, 21 (2), 59-65.

Tellegen, Auke and Gilbert Atkinson (1974), "Openness to Absorbing and Self-Altering Experiences ('Absorption'): A Trait Related to Hypnotic Susceptibility," Journal of Abnormal Psychology, 83 (3), 268-77.

Voss, James F., Jennifer Wiley, and Rebecca Sandak (1999), “On the Use of Narrative as Argument," in Narrative Comprehension, Causality, and Coherence: Essays in Honor of Tom Trabasso, ed. Susan R. Goldman and Arthur C. Graesser, Mahwah, NJ: Erlbaum, 235-52.

Wells, William D. (1988), "Lectures and Dramas," in Cognitive and Affective Responses to Advertising, ed. Pat Cafferata and Alice Tybout, Lexington, MA: D. C. Heath.

Zaichkowsky, Judith L. (1985), "Measuring the Involvement Construct," Journal of Consumer Research, 12 (3), 341-52. 